Ridho, et al/Jurnal Ekonomi Syariah Teori dan Terapan Vol. 6 No. 1 Januari 2019: 1-14; PERILAKU KONSUMSI ISLAMI PARA ALUMNI PONDOK PESANTREN DALAM MENCAPAI KESEJAHTERAAN ISLAM (STUDI KASUS ALUMNI PONDOK PESANTREN ISLAM MIFTACHUS SUNNAH SURABAYA.

\title{
PERILAKU KONSUMSI ISLAMI PARA ALUMNI PONDOK PESANTREN DALAM MENCAPAI KESEJAHTERAAN ISLAM (STUDI KASUS ALUMNI PONDOK PESANTREN ISLAM MIFTACHUS SUNNAH SURABAYA)
}

\author{
Muhammad Ali Ridho \\ Departemen Ekonomi Syariah-Fakultas Ekonomi dan Bisnis-Unversitas Airlangga \\ Email: aliridho.Iumajani@gmail.com \\ Irham Zaki \\ Departemen Ekonomi Syariah-Fakultas Ekonomi dan Bisnis-Unversitas Airlangga \\ Email: irhamzaki0712@gmail.com
}

\begin{abstract}
:
Islamic boarding school can train a santri's Independence and it can be reflected after a santri becomes an alumnus, such as economic welfare. This study aims to determine whether the consumption practice of alumni Islamic boarding school is in line with Islamic welfare or not. The research method used is descriptive qualitative approach by using a case study on alumni of Miftachus Sunnah Islamic boarding school. Data collection is done through in-depth interview, observation and documentation. The validation technique used by source and technique triangulation. The analysis technique used is Miles- Huberman's. The five areas of maqashid sharia in dharuriyyat level stand as indicators of Islamic welfare. The results showed that the consumption practice of alumni of Miftachus Sunnah based on the values (justice, responsibility, and guarantee) and basic principles (efficiency, adequacy, freedom, balance, and solidarity) of Islamic economic behavior in the achievement and guarding of maqashid sharia indicate the suitability.
\end{abstract}

Keywords:Consumption behavior, values of Islamic economic, principal of Islamic economic, and maqashid sharia.

\section{PENDAHULUAN}

\section{Latar Belakang Masalah}

Pondok pesantren adalah salah satu lembaga pendidikan resmi yang ada di Indonesia.Salah satu ciri khas pondok pesantren adalah pendidikan kemandirian santri sebagai subjek utama penuntut ilmu agama di pondok pesantren (Sanusi, 2012:124).

Jumlah pondok pesantren di Indonesia, berdasarkan pendataan oleh Kementrian Agama Republik Indonesia tahun 2014/2015 sebanyak 28.961 pesantren. Jawa Timur menempati urutan kedua dengan lembaga pondok pesantren terbanyak se-Indonesia setelah
Jawa Barat, yaitu 6.044 (20,86\%) pondok pesantren (DITPONTREN, 2016: 180).

Kemandirian merupakan sifat yang bisa diasah dan dilatih. Hasil dari pengasahan serta pelatihan tentang kemandirian santri tersebut bisa dilihat dari banyak aspek setelah menjadi alumni, salah satunya adalah dari aspek kesejahteraan ekonomi.

Pandangan Islam tentang ekonomi dapat ditelusuri dari sejumlah ketentuan dalam al-Qur'an dan hadits sebagai berikut(Nata, 2011: 420):

1. Perintah Mencari Harta

Islam menuntut manusia untuk mencari fad\}lu'I-Lah atau anugerah Allah

1) Artikel ini merupakan bagian dari skripsi dari Muhammad Ali Ridho, NIM : 041311433121, yang diuji pada 3 Mei 2018. 
Ridho, et al/Jurnal Ekonomi Syariah Teori dan Terapan Vol. 6 No. 1 Januari 2019: 1-14; PERILAKU KONSUMSI ISLAMI PARA ALUMNI PONDOK PESANTREN DALAM MENCAPAI KESEJAHTERAAN ISLAM (STUDI KASUS ALUMNI PONDOK PESANTREN ISLAM MIFTACHUS SUNNAH SURABAYA.

guna memenuhi kebutuhan hidupnya (QS. al-Jum'ah: 10).

\section{Perintah Hidup Seimbang}

Pola kehidupan yang seimbang antara urusan dunia dan akhirat sangat dianjurkan dalam Islam (QS. al-Qashash: 77).

3. Harta Sebagai Amanah

Islam memandang harta sebagai amanah dari Allah swt dan hakikat harta semuanya adalah milik-Nya. Maka, pemanfaatan dan penyaluran harta juga harus sesuai dengan ketentuan Allah swt (QS. an-Nisa:5).

4. Harta Sebagai Bekal Ibadah

Adanya harta benda yang dapat dimiliki, memungkinkan manusia untuk dapat beribadah dalam bentuk khusus, seperti zakat, infaq, waqaf, maupun ibadah dalam bentuk umum (QS. Ali 'Imran: 92).

\section{Harta Sebagai Ujian Keimanan}

Harta kekayaan dapat menjadi ujian bagi keimanan seseorang, karena daya tarik harta yang demikian kuat dan sering menyilaukan mata dan menggoda hati (QS. Ali Imran: 14).

Berkaitan dengan pemanfaatan harta yang dimiliki oleh manusia di dunia, Rasulullah bersabda bahwa kelak di akhirat manusia akan ditanya tentang lima hal, salah satunya mengenai dari mana harta yang ia punya dan untuk apa harta tersebut dibelanjakan.

Kegiatan ekonomi sehari-sehari manusia yang berkaitan dengan pemenuhan kebutuhan ekonomi dan pemanfaatan harta tidak terlepas dari tiga kegiatan dasar, yaitu: produksi, distribusi, dan konsumsi. Dari ketiga kegiatan ekonomi tersebut, yang diteliti dalam penelitian ini hanya kegiatan konsumsi.

Proses pemanfaatan dan pembelanjaan harta yang dimiliki manusia harus berdasarkan prinsip-prinsip ekonomi dalam Islam. Disamping itu, dalam mencapai falah (kesejahteraan), perilaku manusia juga perlu dicoraki dengan spirit dan norma dalam Islam yang tercermin dalam nilai-nilai ekonomi Islam (P3El, 2014:65).

Menurut Al-Ghazali dan As-Syatibi tujuan Islam adalah untuk memberikan kesejahteraan kepada orang-orang mukmin dalam iman mereka (ad-diin), hidup (an- nafs), intelektual (al-'aql), anak cucu (an- nasl), dan hak milik (al-mal) atau yang sering disebut sebagai maqashid syariah.

Penelitian ini didasarkan pada fakta bahwa tidak seluruh alumni PPIM bermatapencaharian pada bidang-bidang dengan Upah Minimum Regional (UMR). Peneliti ingin menilik lebih dalam apakah praktik konsumsi para alumni sebagai Iulusan Pondok Pesantren Islam Miftachus Sunnah sudah sesuai dengan nilai dan prinsip dasar ekonomi Islam sebagai salah satu penunjang untuk mencapai kesejahteraan menurut Islam meskipun keadaan ekonomi masing-masing individu berbeda.

\section{Rumusan masalah}

Rumusan masalah dari penelitian ini adalah: Bagaimana perilaku konsumsi Islami para alumni pondok pesantren Islam Miftachus Sunnah dalam mencapai kesejahteraan Islami? 
Ridho, et al/Jurnal Ekonomi Syariah Teori dan Terapan Vol. 6 No. 1 Januari 2019: 1-14; PERILAKU KONSUMSI ISLAMI PARA ALUMNI PONDOK PESANTREN DALAM MENCAPAI KESEJAHTERAAN ISLAM (STUDI KASUS ALUMNI PONDOK PESANTREN ISLAM MIFTACHUS SUNNAH SURABAYA.

\section{Tujuan Penelitian}

Tujuan penelitian ini adalah untuk mengetahui perilaku konsumsi Islami para alumni pondok pesantren Islam Miftachus Sunnah dalam mencapai kesejahteraan Islami.

\section{LANDASAN TEORI}

\section{Pondok Pesantren di Indonesia}

Sudjoko Prasojo dalam Fadli (2012) mendefinisikan pesantren secara lebih jelas sebagai lembaga pendidikan Islam Indonesia untuk mendalami agama Islam dan mengamalkannya sebagai pedoman hidup keseharian (tafaqquh fi'd-din).

Adapun Dhofier dalam Zuhriy (2011)menyebutkan unsur-unsur utama yang terdapat dalam sistem pendidikan pesantren secara tradisional yang menjadikannya khas dan berbeda dengan lembaga pendidikan Islam lainnya adalah kiai, santri, masjid, pondok dan pengajaran kitab-kitab klasik.

Nizar (2007) menyampaikan bahwa pesantren merupakan satu-satunya lembaga kependidikan yang tahan terhadap berbagai gelombang modernisasi. Nilai-nilai progresif dan pengembangan yang bersifat inovatif diadopsi untuk mengejar ketertinggalan darimodel pendidikan lain. Dengan cara demikian, pesantren tetap mampu bersaing dan sekaligus bersanding atau bahkan dapat mengungguli sistem pendidikan modern.

Secara garis besar, pesantrensekarang ini dapat dibedakan menjadi dua macam (Zuhaerini dalam Fadli, 2012), yaitu:
1. Pesantren tradisional (salafiyah), yaitu jenis pesantren yang hanya mengajarkan ilmu-ilmu agama Islam yang bersumber dari kitab-kitab klasik yang ditulis oleh para ulama terdahulu. Metode pengajaran yang digunakan antara lain: sistem sorogan, bandongan, hafalan, dan musyawarah dengan materi pengajaran kitab-kitab kuno yang sering disebut dengan kitab kuning.

2. Pesantren modern (khalafiyah), merupakan pesantren yang di dalamnya mengajarkan ilmu-ilmu agama Islam dan ilmu-ilmu pengetahuan umum sekaligus, tetapi masih tetap mengajarkan kitab- kitab klasik seperti pesantren salafiyah.Tujuan belajar di pesantren adalah tafaqquh fi'ddin atau mempelajari ilmu agama secara mendalam.

Pada akhirnya hasil integrasi ilmuilmu tersebut serta proyeksi pembentukan karakter terhadap para santri bisa mengarahkan pada kesuksesan hidup para Iulusan atau alumni pesantren (Zuhriy, 2011:296-297).

Pelatihan kemandirian santri tidak terlepas dari model pembentukan karakter yang ada di pesantren. Kemandirian ini merupakan salah satu bekal kehidupan yang sangat penting baik ketika masih di pesantren sebagai santri ataupun setelah berada di masyarakat sebagai alumni.

\section{Perilaku Konsumsi Konvensional}

Konsumsi adalah kegiatan menghabiskan utility (nilai guna) barang dan jasa. Istilah barang meliputi barang konsumsi tahan lama dan barang konsumsi tidak tahan lama. Barang konsumsi menurut 
Ridho, et al/Jurnal Ekonomi Syariah Teori dan Terapan Vol. 6 No. 1 Januari 2019: 1-14; PERILAKU KONSUMSI ISLAMI PARA ALUMNI PONDOK PESANTREN DALAM MENCAPAI KESEJAHTERAAN ISLAM (STUDI KASUS ALUMNI PONDOK PESANTREN ISLAM MIFTACHUS SUNNAH SURABAYA.

kebutuhannya, yaitu: kebutuhan primer, kebutuhan sekunder, dan kebutuhan tersier (Samuelson dan Hans, 1993: 101).

Perilaku konsumen merupakan suatu konsep tindakan yang mempelajari bagaimana individu, dan organisasi memilih, membeli, menggunakan produk (barang atau jasa) yang dapat memberikan kepuasan, kebutuhan dan keinginan. Perilaku konsumen adalah tindakan yang langsung terlibat dalam mendapatkan, mengkonsumsi, dan menghabiskan produk dan jasa (Engel JF et al, 1994).

Salah satu bentuk dari konsumsi yang berkaitan dengan kesejahteraan masyarakat adalah distribusi pendapatan. Pendapatan merupakan suatu gambaran tingkat kemampuan seseorang dalam memenuhi kebutuhan materinya dalam satuan waktu tertentu, biasanya per bulan.

Pendapatan dapat diperoleh seseorang dari mata pencaharian utama dengan atau tanpa mata pencaharian lain. Dengan demikian seseorang diharapkan mampu meningkatkan kesejahteraan keluarganya. Kaitannya dengan distribusi pendapatan berarti adanya pendistribusian pendapatan dari satu rumah tanggakonsumsi kepada rumah tangga konsumsi yang lainnya.

\section{Perilaku Konsumsi Islam}

Ekonomi Islam sebagai ilmu ekonomi yang berdasarkan ajaran syariah Islam mengajarkan kepada umat manusia untuk menciptakan kehidupan yang seimbang. Keseimbangan yang dimaksud antara lain mencakup keseimbangan fisik dengan mental, material dan spiritual, individu dengan sosial, masa kini dengan masa depan, serta dunia dan akhirat (P3El, 2014:55).

Chaudhry (2012:137) menyebutkan ada tiga prinsip dasar konsumsi yang digariskan dalam Islam, yaitu:

1. Prinsip Halal. Setiap Muslim diharuskan untuk memakan makanan yang halal (diperbolehkan oleh syariat atau tidak ada larangannya) dan tidak mengambil yang haram (tidak diperbolehkan oleh syariat).

2. Prinsip Kebersihan dan Menyehatkan. Selain halal, barang yang dikonsumsi oleh setiap muslim hendaknya bersih dan menyehatkan.

3. Prinsip Kesederhanaan. Sederhana merupakan sikap tawassut\} antara dua ekstrem kikir dan boros yang merupakan jalan yang dianjurkan oleh Nabi Muhammad SAW.

Karena perhatian ekonomi Islam terletak pada upaya penyejahtaraan manusia dari sisi material sekaligus spiritualnya, maka diperlukan sarana penopang utama, yang menjadi panduan manusia berperilaku sesuai dengan ajaran Islam yaitu moralitas ekonomi (P3EI, 2014:56).

Moral ekonomi Islam dapat diuraikan menjadi dua komponen meskipun dalam praktiknya keduanya masih saling berkaitan, yaitu (P3El, 2014: 57):

1. Nilai Ekonomi Islam.

Inti dari nilai-nilai ajaran Islam yang terdapat dalam Al-Qur'an dan Hadits adalah tauhid yaitu bahwa segala 
Ridho, et al/Jurnal Ekonomi Syariah Teori dan Terapan Vol. 6 No. 1 Januari 2019: 1-14; PERILAKU KONSUMSI ISLAMI PARA ALUMNI PONDOK PESANTREN DALAM MENCAPAI KESEJAHTERAAN ISLAM (STUDI KASUS ALUMNI PONDOK PESANTREN ISLAM MIFTACHUS SUNNAH SURABAYA.

aktivitas manusia di dunia ini, termasuk ekonomi.Dalam pengaplikasiannya, terdapat tiga nilai dasar yang merupakan terjemahan dari nilai tauhid sebagai pembeda ekonomi Islam dengan yang lainnya (P3El, 2014: 58):

a. Adl (Keadilan)

Keadilan adalah hal yang paling pokok dalam ajaran Islam. Menegakkan keadilan dan memberantas kedzaliman adalah tujuan inti dari ajaran para utusanNya (QS. al-Hadid: 25).

b. Khilafah (Tanggung Jawab)

Nilai khilafah secara umum diarahkan kepada tanggung jawab sebagai khalifah di bumi atau wakil Allah SWT untuk memakmurkan bumi dan alam semesta (QS. al-Baqarah: 30).

c. Takaful (Penjaminan)

Islam mengajarkan bahwa antara muslim satu dan lainnya adalah saudara yang diibaratkan sebuah rumah. Hal inilah yang memotivasi manusia untuk menciptakan hubungan yang baik di antara individu dalam masyarakat melaluikonsep penjaminan sosial atau Takaful (QS. at-Taubah: 60).

2. Prinsip Dasar Ekonomi Islam

Prinsip-prinsip yang menjadi pedoman pokok dalam membangun struktur ekonomi Islam adalah sebagai berikut (P3El, 2014: 66):

a. Kerja (resource utilization) Kerja dapat didefinisikan sebagai pemanfaatan atas kepemilikan sumber daya, baik oleh pemiliknya sendiri atau oleh pihak lain.

b. Kompensasi (compensation).Prinsip ini merupakan bentuk keluaran dari implementasi prinsip kerja.

c. Efisiensi (efficiency). Efisiensi merupakan perbandingan terbaik antara kegiatan pengelolaan sumber daya dengan hasilnya.

d. Profesionalisme (professionalism). Profesional berarti menyerahkan suatu urusan pengelolaan kepada ahlinya sehingga diperoleh output yang maksimal.

e. Kecukupan (sufficiency). Jaminan kelayakan ini bukan hanya pada tingkatan darurat saja, tetapi juga kenyamanan hidup.

f. Pemeretaan kesempatan (equal opportunity). Setiap individu memiliki kesempatanyang sama untuk, mencari, memiliki, mengelola sumber daya, dan menikmatinya sesuai dengan kemampuannya.

g. Kebebasan (freedom). Manusia diberi akal dan nafsu untuk menentukan arah pilihan hidup. Islam memberikan kebebasan kepada manusia untuk memiliki sumber daya, mengelolanya dan memanfaatkannya untukmencapai kesejahteraan hidup dengan ketentuan yangtelah digariskan dalam Islam.

h. Kerjasama (cooperation). Kerjasama adalah upaya untuk saling mendorong dan menguatkan satu 
Ridho, et al/Jurnal Ekonomi Syariah Teori dan Terapan Vol. 6 No. 1 Januari 2019: 1-14; PERILAKU KONSUMSI ISLAMI PARA ALUMNI PONDOK PESANTREN DALAM MENCAPAI KESEJAHTERAAN ISLAM (STUDI KASUS ALUMNI PONDOK PESANTREN ISLAM MIFTACHUS SUNNAH SURABAYA.

sama lain dalammencapaitujuan bersamayang telah ditentukan.

i. Persaingan (competition). Termasuk pula dalam halmuamalah, Islam mengatur kebebasan bersaing dalam pasar selama tidak ada monopoli atau bentuk perdaganganlain yang memicu tidakstabilnya kondisi pasar.

j. Keseimbangan (equilibrium). Keseimbanga njuga berarti terciptanya suatu kondisi dimana tidak ada satu pihak pun yang merasa dirugikan, atau kondisi saling ridho. Hal ini lah yang dimaksud sebagai keseimbangan pasar.

k. Solidaritas (solidarity). Solidaritas dalam konteksini mengandung arti persaudaraan dan tolongmenolong. Keduanya adalah unsur pokok dalam memupuk hubungan yang baik antar sesame dalam segala aspek kehidupan

I. Informasi simetri (symmetric information). Kejelasan informasi sangat diperlukan dalam bermuamalah, agar tidak ada pihak yang merasa dirugikan

\section{Kesejahteraan}

Kesejahteraan adalah kondisi agregat dari kepuasan individu- individu. Kesejahteraan menurut kamus bahasa Indonesia berasal dari kata sejahtera yang berarti aman, sentosa, makmur dan selamat (terlepas dari segala macam gangguan, kesukaran, dan lain sebagainya) (Poerwadarminto, 1999: 887).
Pada sisi konsumsi, kesejahteraan bisa diukur dengan menghitung seberapa besar pengeluaran yang dilakukan seseorang atau sebuah keluarga untuk memenuhi kebutuhan sandang, pangan, papan, serta kebutuhan lainnya dalam periode tertentu.Islam memandang kesejahteraan sebagai al-falah atau secara bahasa berarti kemenangan, yaitu kesejahteraan secara menyeluruh dan seimbang antara material- spiritual, individusosial, serta kesejahteraan kehidupan di dunia maupun akhirat.

Perilaku manusia di dunia diyakini akan berpengaruh terhadap kesejahteraan di akhirat yang abadi. Chaudhry (2012: 157) menyatakan bahwa Islam tidak memberi batas minimum atau maksimum dalam standart of living para pemeluknya. Inti dari prinsip dasar sistem ekonomi Islam adalah bahwa setiap umat muslim harus dapat memenuhi paling tidak kebutuhan dasarnya.

Ada banyak instrumen filantropi dalam Islam yang tergolong kegiatan pendistribusian pendapatan pada intinya memiliki tujuan yang sama, yaitu untuk mensejahterahkan umat. Adapun instrument-instrumen filantropi tersebut antara lain: zakat, infaq, dan shodaqoh. Masing- masing memiliki mustahiq (orang yang berhak menerima) yang berbedabeda serta karakteristik dan ketentuan yang berbeda pula. Namun, secara umum fakir dan miskin termasuk mustahik ketiganya.

Berkaitan dengan tujuan Islam untuk menyejahterakan umat. Menurut As-Syatibi (w. $790 \mathrm{H}$ ) dalam kitabnya yang berjudul al- 
Ridho, et al/Jurnal Ekonomi Syariah Teori dan Terapan Vol. 6 No. 1 Januari 2019: 1-14; PERILAKU KONSUMSI ISLAMI PARA ALUMNI PONDOK PESANTREN DALAM MENCAPAI KESEJAHTERAAN ISLAM (STUDI KASUS ALUMNI PONDOK PESANTREN ISLAM MIFTACHUS SUNNAH SURABAYA.

muwafaqat dijelaskan bahwa taklif (pembebanan) syariat itu kembali pada pelestarian tujuan aslinya. Pembagian tujuan tersebut tidak terlepas dari tiga tingkatan: dharuriyat (kebutuhan dasar), hajiyat (kenyamanan atau rekreatif), dan tahsiniyat (kemewahan).

Al-Ghazali $(450-505 \mathrm{H})$ menerangkan sebagai pelengkap dari penjelasan Imam As-Syatibi bahwa tujuan pemenuhan tersebut tidak lain adalah untuk mencapai maslahah. Lebih lanjut beliau menjelaskan bahwa maslahah tidak sebatas mengambil manfaat dari sesuatu dan menghilangkan madharat manusia atau makhluk saja, karena jika sebatas itu, maka kemaslahatan manusia atau makhluk secara umum merupakan tujuan inti mereka. Namun, lebih dari itu maslahah adalah bagaimana pelestarian dan penjagaan pada tujuantujuan syariah yang ada.

Tujuan-tujuan syariah inilah yang menjadi inti dari pencapaian maslahah.tersebut. Tujuan syariah atau maqashid syariah terbagi dalam lima hal, yaitu: iman (ad-diin), hidup (an-nafs), ntelektual (al 'aql), keturunan (an-nasl), dan hak milik (al- mal) (P3El, 2008:6).

\section{METODE PENELITIAN}

\section{Pendekatan Penelitian}

Berdasarkan rumusan masalah yang melatarbelakangi penelitian ini Pendekatan yang digunakan adalah pendekatan kualitatif deskriptif. Menurut Yin (2002: 4) penelitian kualitatif merupakan penelitian yang biasanya digunakan untuk meneliti persoalan-persoalan sosial, pendidikan, maupun komunikasi, penelitian ini melihat permasalahan dari berbagai disiplin ilmu, ranah, subyek permasalahan.

Jenis penelitian yang digunakan merupakan penelitian studi kasus. Yin (2002: 5) mengatakan bahwa penelitian studi kasus adalah suatu metode yang secara khusus menyelidiki fenomena yang terdapat dalam konteks kehidupan nyata, yang dilakukan ketika batasan-batasan antara fenomena dan konteksnya belum jelas dan memanfaatkan berbagai sumber.

\section{Ruang Lingkup dan Waktu Penelitian}

Sugiyono (2012: 207) memberikan batasan dalam penelitian kualitatif lebih didasarkan pada tingkat kepentingan, urgensi, dan fasibilitas masalah yang akan dipecahkan, selain juga faktor keterbatasan tenaga, dana, dan waktu.

Peneliti membuat gambaran sederhana dalam mengukur kesejahteraan sesorang muslim berdasarkan Al-Qur'an, hadits, dan mengacu pada pemikiranpemikiran para ekonom muslim, antara lain terpenuhinya: 1). Kebutuhan dharuriyyat (sandang, pangan, dan papan), 2). keseimbangan kebutuhan spiritual, sosial, dan individu, 3). Tidak termasuk golongan fakir, 4). Keamanan dan perlindungan terhadap keluarga, dan 5) Perilaku ekonomi yang tidak keluar dari koridor syariah.

Penelitian ini dilaksanakan antara bulan Mei - Desember 2017 dengan melibatkan beberapa alumni pondok pesantren sebagai narasumber dan penguat data. 
Ridho, et al/Jurnal Ekonomi Syariah Teori dan Terapan Vol. 6 No. 1 Januari 2019: 1-14; PERILAKU KONSUMSI ISLAMI PARA ALUMNI PONDOK PESANTREN DALAM MENCAPAI KESEJAHTERAAN ISLAM (STUDI KASUS ALUMNI PONDOK PESANTREN ISLAM MIFTACHUS SUNNAH SURABAYA.

\section{Jenis dan Sumber Data}

Berdasarkan sumbernya terdapat dua jenis sumber data yang dapat dijadikan sebagai bahan penelitian oleh peneliti, diantaranya adalah: data primer yang dapat diperoleh dari sumber utama yaitu informan dari pihak alumni Pondok Pesantren Islam Miftachus Sunnah dengan melakukan wawancara secara langsung kepada pihak-pihak yang terkaitan dan data sekunder yang tidak dapat secara langsung memberikan data kepada pengumpul data.

\section{Teknik penentuan Informan}

Kriteria informan yang dibutuhkan dalam penelitian ini adalah:

1. Beragama Islam

2. Laki-laki

3. Alumni Pondok Pesantren Islam Miftachus Sunnah. Dengan masa belajar di atas 6 tahun (dengan asumsi telah menyelesaikan minimal dua tingkat pendidikan .

Pemilihan informan menggunakan purposive sampling yang berarti teknik pengambilan data dengan pertimbangan tertentu.

\section{Unit Analisis dan Pertanyaan Protokol}

Penentuan unit analisis dengan menentukan informan dari penelitian dan menentukan pertanyaan protokol dalam studi kasus. Menurut Yin (2003: 82) protokol studi kasus merupakan strategi umum dalam meningkatkan reliabilitas penelitian model studi kasus dan dimaksudkan untuk membimbing peneliti dalam melaksanakan studi kasusnya.
Unit analisis untuk mengetahui perilaku ekonomi yang dimaksud ditinjau dari masing-masing lima maqashid syariah, yaitu:

1. Din (Agama): Mengenai rukun Islam dan ibadah-ibadah sunnah lain.

2. Nafs (Jiwa) : Mengenai kesehatan jiwa dan raga

3. Aql (Akal) : Mengenai pendidikan, pemilihan lembaga pendidikan, dan keikutsertaan pelatihan, seminar, workshop penunjang profesi.

4. Mal (Harta) : Mengenai rukun Islam dan sedekah sunnah

5. Nasl (Keturunan) : Pendidikan anak dan pendidikan akhlag anak.

\section{Teknik Pengumpulan Data}

Penelitian ini menggunakan metode pengumpulan data sebagai berikut:

1. Wawancara. Wawancara dalam penelitian ini, dipilih wawancara semi terstruktur karena untuk mendapatkan informasi yang lebih dalam. Apabila dalam pelaksanaan wawancara dirasa ada informasi yang dapat terus digali guna memperdalam deskripsi, maka hal itu perlu dilakukan. Namun, jika dirasa dari pertanyaan yang sudah disediakan, informasi tidak berkembang dan dirasa cukup, maka wawancara dapat dihentikan.

2. Observasi partisipan. Observasi partisipan yang dimaksud dalam penelitian ini adalah peneliti melakukan observasi secara langsung terhadap kegiatan para informan yang berkaitan dengan kegiatan ekonomi (konsumsi ). 
Ridho, et al/Jurnal Ekonomi Syariah Teori dan Terapan Vol. 6 No. 1 Januari 2019: 1-14; PERILAKU KONSUMSI ISLAMI PARA ALUMNI PONDOK PESANTREN DALAM MENCAPAI KESEJAHTERAAN ISLAM (STUDI KASUS ALUMNI PONDOK PESANTREN ISLAM MIFTACHUS SUNNAH SURABAYA.

3. Dokumen

Penggunaan dokumen paling penting adalah untuk mendukung dan menambah bukti dari sumber-sumber lain (Yin, 2003:104).

Sumber data dari dokumen memilikiperan penting untuk memperkuat hasil penelitian.

Teknik Keabsahan Data

Triangulasi adalah teknik pengumpulan data dengan cara menggabungkan dari berbagai teknik pengumpulan data dan sumber yang sudah ada (Sugiyono, 2010: 241).

Teknik triangulasi yang digunakan dalam penelitian ini adalah traingulasi sumber. Peneliti melakukan crosscheck antar data informan utama kepada informan lain yang berkaitan. Informan lain yang berkaitan adalah pihak yang mengetahui sebagian besar kegiatan sehari-hari informan utama. Penelitian ini juga melakukan pengecekan validitas data dengan dokumen terkait.

\section{Teknik Analisis Data}

Menurut Yin (2013: 140) bentuk teknik analisis data yang dapat digunakan dalam penelitian studi kasus adalah sebagai berikut:

1. Penjodohan pola (pattern matching).Teknik analisis pattern matching ini menggunakan logika penjodohan pola.

2. Pembuatan penjelasan (explanation building). Teknik analisis ini bertujuan untuk menganalisis data studi kasus dengan cara membuat suatu penjabaran tentang kasus yang bersangkutan untuk keberlanjutan suatu penelitian.

3. Analisis deret waktu (time-series analysis). Teknik analisis deret waktu hampir miripdengan teknik analisis penjodohan pola. Perbedaannnya terletak pada pola yang dijodohkan. Analisis deret waktu lebih menekankan pada kronologi suatu peristiwa (pendekatan eksperimen).

Proses analisis data sebuah penelitian dapat menggunakan teori Miles dan Huberman (Miles dan Huberman, 1992 dalam Yin, 2009), yang dikelompokkam menjadi tiga langkah dasar:

1. Data Reduction (Reduksi Data). Reduksi data yaitu proses pemilihan, pemutusan perhatian dan penyederhanaan, pengabstrakan dan transformasi data kasar yang muncul dari catatancatatan tertulis di lapangan (Miles dan Huberman 1992: 16). Data yang diperoleh dari hasil wawancara dan observasi yang

2. Data Display (Penyajian Data). Penyajian data adalah sekumpulan informasi tersusun dan memberikankemungkinan adanya penarikan kesimpulandan pengambilan tindakan berikutnya.

3. Conclusion Drawing / Verification (Menarik Kesimpulan/ Verifikasi). Pada proses ini, peneliti akan menarik kesimpulan awal dari data yang diperoleh dengan metode triangulasi melalui wawancara dan dokumentasi. Kesimpulan wawancara dan 
Ridho, et al/Jurnal Ekonomi Syariah Teori dan Terapan Vol. 6 No. 1 Januari 2019: 1-14; PERILAKU KONSUMSI ISLAMI PARA ALUMNI PONDOK PESANTREN DALAM MENCAPAI KESEJAHTERAAN ISLAM (STUDI KASUS ALUMNI PONDOK PESANTREN ISLAM MIFTACHUS SUNNAH SURABAYA.

dokumentasi. Kesimpulan awal tersebut dapat berubah apabila tidak didapat bukti-bukti yang mendukung padatahap pengumpulan data selanjutnya.

\section{HASIL DAN PEMBAHASAN}

\section{Pembahasan}

Pondok pesantren Islam Miftachus Sunnah (PPIM) merupakan salah satu pondok pesantren yang berada di Surabaya, Jawa Timur.

Keunikan dari pesantren ini yaitu lokasinya yang terletak di jantung Kota Surabaya. Ini menjadi salah satu tantangan tambahan yang dihadapi oleh santri pondok pesantren Miftachus Sunnah. Sistem pendidikannya memakai acuan, sistem salaf, tapi bagian pendidikan pondok pesantren Islam Miftachus Sunnah juga tetap mengikuti arus pendidikan nasional yang telah ditetapkan oleh undangundang.

Tabel 1.

Tingkatan Pendidikan di PP. Miftachus Sunnah

\begin{tabular}{|c|c|c|c|}
\hline Tingkat & $\begin{array}{c}\text { Nama } \\
\text { Lembaga }\end{array}$ & $\begin{array}{c}\text { Masa } \\
\text { Pendidika } \\
\mathrm{n}\end{array}$ & Keterangan \\
\hline RA/TK & $\begin{array}{c}\text { RA } \\
\text { DarulHijroh }\end{array}$ & 2 Th. & \\
\hline $\mathrm{Ml} / \mathrm{SD}$ & $\begin{array}{c}\text { MI } \\
\text { DarulHijroh. }\end{array}$ & $6 \mathrm{Th}$. & \\
\hline $\begin{array}{l}\text { MTs/ } \\
\text { SMP }\end{array}$ & \multirow{4}{*}{$\begin{array}{c}\text { MadrasahDini } \\
\text { yyah Darul } \\
\text { Hijroh }\end{array}$} & \multirow[t]{2}{*}{$6 \mathrm{Th}}$. & $\begin{array}{l}\text { Kelas } 1-3 \\
\text { Tamhidiyah }\end{array}$ \\
\hline $\begin{array}{l}\text { MA/ } \\
\text { SMA }\end{array}$ & & & $\begin{array}{l}\text { Kelas } 4-6 \\
\text { Tamhidiyah }\end{array}$ \\
\hline $\begin{array}{c}\text { Takhos } \\
\text { us }\end{array}$ & & 6 Th. & $\begin{array}{c}\text { Untuk } \\
\text { Umum }\end{array}$ \\
\hline $\begin{array}{l}\text { Wasthi } \\
\text { yyah }\end{array}$ & & 3 Th. & $\begin{array}{c}\text { Lanjutan } \\
\text { dari } \\
\text { Tamhidiyya } \\
\text { h dan } \\
\text { Takhosus } \\
\end{array}$ \\
\hline
\end{tabular}

Sumber: Data Olahan Yayasan PPIM (2014)

Pada waktu UN dilaksanakan, merekadiikutkan ujian pada sekolah yang telah memiliki hubungan kerjasama dengan pesantren Miftachus Sunnah.

Tabel 2.

Data Sebaran Alumni Berdasarkan Pekerjaan

\begin{tabular}{|c|l|c|l|}
\hline No & \multicolumn{1}{|c|}{$\begin{array}{c}\text { Mata } \\
\text { Pencaharian }\end{array}$} & $\begin{array}{c}\text { Jumlah } \\
\text { Alumni } \\
\text { (t orang) }\end{array}$ & Pendapatan \\
\hline 1. & PNS & 20 & $\begin{array}{l}\text { UMR dengan } \\
\text { Tunjangan }\end{array}$ \\
\hline 2. & Guru Diniyyah & 25 & $\begin{array}{l}\text { Rp. 100.000 / } \\
\text { bulan tanpa } \\
\text { tunjangan }\end{array}$ \\
\hline 3. & Guru Formal & 50 & $\begin{array}{l}\text { Rp.300.000/bul } \\
\text { an dengan } \\
\text { tunjangan }\end{array}$ \\
\hline 4. & Wiraswasta & 200 & $\begin{array}{l}\text { Rp. 100.000 / } \\
\text { hari }\end{array}$ \\
\hline 5. & $\begin{array}{l}\text { Pegawai } \\
\text { Swasta }\end{array}$ & 300 & $\begin{array}{l}\text { UMR Tanpa } \\
\text { Tunjangan }\end{array}$ \\
\hline 6. & Buruh & 300 & $\begin{array}{l}\text { Rp 100.000,- / } \\
\text { Bulan }\end{array}$ \\
\hline
\end{tabular}

Sumber: Data IKASMI2016Pembahasan.

Hasil dari proses pembelajaran santri di pondok pesantren akan terlihat saat ia menjadi seorang alumni atau lulusan dari pondok pesantren tersebut. Alumni dalam penelitian ini ditujukan untuk para santri yang telah menyelesaikan seluruh tingkatan pendidikan di Pondok Pesantren Islam Miftachus Sunnah dan bermukim di dalamnya dalam kurun waktu lebih dari enam tahun.

Berpedoman pada Al-Qur'an danHadits disertai dengan pemikiran para ekonom Muslim dalam merumuskan perilaku ekonomi yang tercakup pada bagian figh muamalah, penelitian ini menghasilkan sebuah gambaran umum secara komprehensif perihal nilai dan prinsip yang menjadi acuan para alumni dalam berkegiatan konsumsi dan kaitannya dengan pencapaian kesejahteraan para alumni berdasarkan pencapaian maqashid syariah. 
Ridho, et al/Jurnal Ekonomi Syariah Teori dan Terapan Vol. 6 No. 1 Januari 2019: 1-14; PERILAKU KONSUMSI ISLAMI PARA ALUMNI PONDOK PESANTREN DALAM MENCAPAI KESEJAHTERAAN ISLAM (STUDI KASUS ALUMNI PONDOK PESANTREN ISLAM MIFTACHUS SUNNAH SURABAYA.

Hasil dari penelitian ini menggambarkan bahwa para informan yang merupakan alumni PP. Miftachus Sunnah sangat memperhatikan penjagaan terhadap terpenuhinya kelima bidang maqashid syariah:

1. Agama (ad-din)

Ibadah sholat yang merupakan tiang agama mendapatkan perhatian yang besar dalam pelaksanannya. Hal ini dilihat dari keistiqomahan untuk menyempurnakan pahala sholat dengan melakukannya secara berjamaah dan mengiringinya dengan ibadah-ibadah sunnah lain.

Meskipun Haji merupakan rukun Islam yang paling mahal, para informan sepakat untuk tetap berusaha dalam menunaikannya dengan cara menabung.Para informan juga meyakini bahwa meski lbadah sunnah sebagai pelengkap Ibadah wajib juga tidak bolehdikesampingkan. Kebiasaan melakukan ibadah-ibadah sunnah ini merupakan buah ajaran dari pondok dan atau para informan sudah merasakan manfaatnya untuk dalam kehidupan mereka.

2. Jiwa dan Raga (an-nafs)

Jiwa merupakan bagian penting dari an-nafs. Kesehatan jiwa juga merupakan hal penting sebagaimana kesehatan raga yang harus dijaga. Penjagaan kesehatan jiwa ini dilakukan oleh para informan dengan cara mengikuti tarekat-tarekat, membaca dzikir rutin, dan melakukan ibadahibadah sunnah lain yang dapat menentramkan hati jika diiringi dengan mengingat kebesaran Allah swt.

Para informan yang juga alumni PP. Miftachus Sunnah berpendapat, ada berbagai cara untuk menjaga kesehatan raga yang termasuk bagian dari an-nafs, antara lain: olahraga rutin, menjaga pola makan, menjaga pola tidur, tidak mengkonsumsi makanan yang tidak baik untuk kesehatan, dan mengkonsumsi suplemen tambahan, seperti minuman herbal, madu, dll.

3. Akal (Aql)

Pentingnya pendidikan menjadikannya sebagai jalur utama untuk mencapai kebahagiaan dunia dan akhirat bagi para informan. Selain memang pendidikan merupakan kewajiban syariat Islam melalui perintah menuntut ilmu, baik ilmu sains ataupun ilmu agama.

Untuk mendapatkan pendidikan yang berkualitas tinggi dalam bidang yang diinginkan, maka harus disesusaikan dengan lembaga pendidikannya. Sekolah formal untuk pendidikan ilmu sains (dunia) dan Pesantren untuk pendidikan ilmu agama (akhirat). Selain menempuh jalur pendidikan sesuai dengan bidang masing-masing, dapat ditambah pula dengan mengikuti pelatihan, seminar, dan workshop untuk mengupgrade keilmuan yang dimiliki sebagai penunjang profesi yang sedang dijalani.

4. Harta (Mal)

Zakat merupakan rukun Islam ke-3 yang diwajibkan kepadasetiap muslim. 
Ridho, et al/Jurnal Ekonomi Syariah Teori dan Terapan Vol. 6 No. 1 Januari 2019: 1-14; PERILAKU KONSUMSI ISLAMI PARA ALUMNI PONDOK PESANTREN DALAM MENCAPAI KESEJAHTERAAN ISLAM (STUDI KASUS ALUMNI PONDOK PESANTREN ISLAM MIFTACHUS SUNNAH SURABAYA.

Salah satu fungsi zakat adalah untuk menjaga maqashid syariah berupa jiwa (zakat fitrah) dan harta (zakat mal). Zakat fitrah dikeluarkan setiap tahun pada bulan Ramadhan hingga sebelum dilaksanakannya sholat Idul Fitri berupa zakat makanan pokok. Sedangkan zakat mal memiliki beberapa syarat termasuk haul dan nishob sebelum mengeluarkannya.

Islam memiliki banyak alternatif dalam hal pendistribusian harta benda. Pelaksanaan sedekah ini bergantung pada para informan yang melaksanakannya, ada yang beralasan karena memang disyariatkan oleh agama, alasan sosial, ataupun tujuan untuk keberkahan harta yang dimiliki.

5. Keturunan (Nasl)

Anak merupakan generasi penerus yang harus dijaga tidak hanya eksistensinya, tapi juga kualitasnya. Salah satu cara untuk menjaga kualitas anak (keturunan) menurutpara informan adalah dengan memberikannya pendidikan.

Pendidikan yang dimaksud disiniadalah pendidikan di sekolah formal ataupun informal. Menurut mereka, mahal tidaknya suatu sekolahan bukan menjadi tolak ukur kualitas ilmu pengetahuan yang diajarkan di dalamnya, tapi itu bisa dijadikan sebagai acuan seberapa besar pengorbanan orang tua agar anak mendapatkan pendidikan yang berkualitas.
Selain pendidikan di sekolah formal atau pesantren (informal), pendidikan akhlaq dari orang tua juga merupakan hal yang utama. Hal ini berkaitan dengan penyesuaian anak bersikap terhadap orang lain atau kepada lingkungan sekitar.

Pendidikan akhlaq ini juga terkait dengan kedisiplinan anak dalam kehidupan sehari-hari. Pesantren juga merupakan lembaga pendidikan yang menawarkan pengajaran mengenai akhlaq ini dan mayoritas orang tua memilih pesantren sebagai rujukan pendidikan akhlak putra- putrinya selain juga untuk belajar formal.

Kelima maqashid syariah tersebut sebagai indikator dalam pencapaian kesejahteraan menurut Islam. Karena masing-masing dari maqashid syariah tersebut telah terpenuhi oleh para informan, hal selanjutnya yang dilihat dalam penelitian ini adalah keterkaitan dari perilaku konsumsi Islami para informan yang dilihat dari nilai dan prinsip dasar ekonomi Islam yang terkandung dalam perilaku konsumsi mereka dengan kesejahteraan Islam itu sendiri.

Hasilnya menunjukkan bahwa perilaku konsumsi para informan yang mengandung nilai dan prinsip dasar ekonomi Islam itulah yang memang menjadi salah satu faktor mereka dalam mencapai kesejahteraan menurut Islam.

\section{Keterbatasan Penelitian}

Penelitian ini telah dilaksanakan secara sistematis sesuai dengan prosedur ilmiah.Namun, penelitian ini masih memiliki 
Ridho, et al/Jurnal Ekonomi Syariah Teori dan Terapan Vol. 6 No. 1 Januari 2019: 1-14; PERILAKU KONSUMSI ISLAMI PARA ALUMNI PONDOK PESANTREN DALAM MENCAPAI KESEJAHTERAAN ISLAM (STUDI KASUS ALUMNI PONDOK PESANTREN ISLAM MIFTACHUS SUNNAH SURABAYA.

kekurangan yaitu, tidak ditemukannya indikator dan instrumen yang baku dalam menentukan kesejahteraan Islami. Penggunaan maqashid syariah sebagai tolak ukur kesejahteraan menurut Islam karena di dalamnya terdapat tujuan-tujuan yang menjadi parameter keberhasilan seorang muslim dalam mencapai falah atau kesejahteraan

\section{SIMPULAN}

1.Praktikkonsumsilslami para alumni pondok pesantrenMiftachus Sunnah berlandaskannilai dan prinsipdasar perilakuekonomi Islam.

2.Praktikkonsumsi yang berlandaskannilai danprinsipdasarperilakuekonomi Islam sangatmenunjangdalam mencapai kesejahteraan menurutlslam.

3.Nilaidan prinsipdasarekonomi Islam tersebut,yaitu:

a. Nilaiekonomi Islam:Keadilan(adl), Tanggung Jawab (khilafah), dan Penjaminan (Takaful).

b. Prinsip dasar ekonomilslam: Efisiensi (efficiency), Kecukupan (sufficiency), Kebebasan (freedom)

\section{DAFTAR PUSTAKA}

AlQur'an danHadits.

Al-Ghazali, Abu Hamid Muhammad bin Muhammad.tt. Al-Mustashfa. Jilid II. Fakultas Syariah Universitas Islam Madinah Nama pengarang. Tahun. Judul. Nama penerbit atau volume. As-Syatibi, Ibrahim bin Musa. 1997. AlMuwafaqat. Jilid II. Al-Aqrabiyah: Dar Ibnu Affan. Chaudhry,
Muhammad Sharif. Tanpa Tahun. Sistem Ekonomi Islam: Prinsip Dasar.Terjemahan oleh Suherman Rosidi. 2012. Jakarta: Kencana.

DITPONTREN. 2016. Analisis dan Interpretasi Data pada Pondok Pesantren, Madrasah Diniyah (Madin), Taman Pendidikan Qur'an (TPQ) Tahun Pelajaran 2014-2015

Fadli, Adi. 2012. Pesantren: Sejarah dan Perkembangannya. EL-HIKAM: Jurnal Pendidikan dan Kajian Keislaman, Vol. V Nomor 1, Januari - Juni: 29-42

Nata, Abdullah. 2011. Studi Islam Komprehensif. Edisi Pertama, Cet. ke-1. Jakarta : Kencana.

Nizar, Samsul (Editor). 2007. Sejarah Pendidikan Islam. Jakarta: Kencana. Poerwadarminto, WJS. 1999. Kamus UmumBahasa Indonesia. Jakarta: Balai Pustaka.

Pusat Pengkajian dan Pengembangan Ekonomi Islam. 2008. Ekonomi Islam. Edisi Kesatu. Jakarta: PT Raja Grafindo Persada

2014. Ekonomi Islam. Edisi Kesatu. Cet. ke-6. Jakarta: PT Raja Grafindo Persada.

Samuelson, Paul dan William D Nor Hans. 1993. Ekonomi. Jilid I. Jakarta:Airlangga.

Sanusi, Uci. 2012. Pendidikan Kemandirian Di Pondok Pesantren (Studi Mengenai Realitas Kemandirian Santri di Pondok al-Istiqlal Cianjur dan Pondok Pesantren Bahrul Ulum Tasikmalaya). Jurnal Pendidikan 
Ridho, et al/Jurnal Ekonomi Syariah Teori dan Terapan Vol. 6 No. 1 Januari 2019: 1-14; PERILAKU KONSUMSI ISLAMI PARA ALUMNI PONDOK PESANTREN DALAM MENCAPAI KESEJAHTERAAN ISLAM (STUDI KASUS ALUMNI PONDOK PESANTREN ISLAM MIFTACHUS SUNNAH SURABAYA.

Agama Islam- Ta'lim, Vol. 10 No. 2: 123- 139

Sugiyono. 2012. Metode Penelitian Kualitatif dan Kuantitatif R\&D. Bandung: Alfabeta

Yin, Robert K. 2002. Studi kasus: Desain dan Metode, Terjemahan. Jakarta: PT. Raja Grafindo Persada.

-. 2009. Studi kasus: Desain dan Metode, Terjemahan. Jakarta: PT. Raja Grafindo Persada.
Zuhriy, M. Syaifuddien. 2011. Budaya Pesantren dan Pendidikan Karakter pada Pondok Pesantren Salaf. Walisongo, Vol. 19, No. 2, November:287-310 